\title{
Strategies for Generating Diverse Antibody Repertoires Using Transgenic Animals Expressing Human Antibodies
}

Weihsu C. Chen and Christopher M. Murawsky*

Biologics Discovery, Department of Therapeutic Discovery, Amgen British Columbia Inc., Burnaby, BC, Canada

Therapeutic molecules derived from antibodies have become a dominant class of drugs used to treat human disease. Increasingly, therapeutic antibodies are discovered using transgenic animal systems that have been engineered to express human antibodies. While the engineering details differ, these platforms share the ability to raise an immune response that is comprised of antibodies with fully human idiotypes. Although the predominant transgenic host species has been mouse, the genomes of rats, rabbits, chickens, and cows have also been modified to express human antibodies. The creation of transgenic animal platforms expressing human antibody repertoires has revolutionized therapeutic antibody drug discovery. The observation that the immune systems of these animals are able to recognize and respond to a wide range of therapeutically relevant human targets has led to a surge in antibody-derived drugs in current development. While the clinical success of fully human monoclonal antibodies derived from transgenic animals is well established, recent trends have seen increasingly stringent functional design goals and a shift in difficulty as the industry attempts to tackle the next generation of disease-associated targets. These challenges have been met with a number of novel approaches focused on the generation of large, high-quality, and diverse antibody repertoires. In this perspective, we describe some of the strategies and considerations we use for manipulating the immune systems of transgenic animal platforms (such as XenoMouse $^{\circledR}$ ) with a focus on maximizing the diversity of the primary response and steering the ensuing antibody repertoire toward a desired outcome.

Keywords: antibody, repertoire, transgenic, therapeutic, engineering, B cell, diversity, immune

\section{INTRODUCTION}

The remarkable capacity of engineered animals to utilize human antibody sequences to functionally replace their own has allowed researchers to harness the power of the natural humoral immune response. Antibody generation in vivo offers several advantages, including the ability to readily recover molecules that bind to the target antigen with high specificity and affinity (1). The processes of in vivo sequence diversification, antigen-driven somatic hypermutation, and numerous quality control checkpoints ensure the non-random selection and enrichment of B cells that produce antibodies with therapeutically desirable properties $(2-5)$.

Despite the demonstrated successes of transgenic platforms, researchers face significant challenges related to the increasing complexity of functional design goals and targets. Ideal antibody 
candidates are often required to bind with high affinity to a specific epitope, cross-react to a non-human ortholog, lack binding to paralogs, and survive the rigors of the stringent drug development process (6). Thus, antibodies satisfying all the design goals may be extremely rare, if they are elicited at all. At the same time, the targets themselves have shifted in difficulty from the "low-hanging fruit" to those that are considerably more challenging (7-11). In this perspective, we will highlight the strategies and considerations used for manipulating the immune systems of transgenic animal platforms. We will first concentrate on the transgenic platforms and call out specific features that contribute to forming antibody repertoires. We will then draw from our experience using XenoMouse ${ }^{\circledR}$ to discover novel human therapeutics and focus on the approaches we use to maximizing the diversity of the primary antibody repertoire and to steer it toward the desired outcome.

\section{TRANSGENIC PLATFORMS EXPRESSING HUMAN ANTIBODY REPERTOIRES}

The collection of unique B cells in an organism (the B-cell repertoire) encodes and produces the corresponding antibody repertoire. Herein, we will use "antibody repertoire" to describe the collection of sequence-unique antibodies, and their corresponding B cells, present in a given system. Transgenic animal platforms expressing human antibodies utilize the in vivo biology of the host immune system to generate diversity through canonical recombination and somatic hypermutation. Importantly, both the breadth and shape of the antibody repertoire can be influenced to yield a desired response.

The demonstration that large portions of the intact human immunoglobulin loci could be introduced into the mouse genome was a significant achievement and is the subject of a series of excellent reviews $(1,12-14)$. These efforts culminated in the world's first fully human transgenic antibody generation platforms (XenoMouse ${ }^{\circledR}$ and HuMab-Mouse ${ }^{\circledR}$ ) and have been followed by a series of related, next-generation animals (15-20). These platforms largely recapitulate critical aspects of the human antibody repertoire including $\mathrm{V}$-, D-, and J-segment usage patterns. The remarkable ability of these animals to assimilate mouse biology and human antibody sequence information has revolutionized biotechnology by providing access to a diverse source of fully human antibodies. The number of marketed human therapeutics derived from these platforms, and their continued use as engines for de novo antibody discovery, highlights their success (21).

Three exciting, emerging trends in this area are as follows: (1) the development of human antibody generation platforms in species other than mouse, (2) the creation of transgenic systems that produce non-canonical antibodies, and (3) attempts to genetically manipulate the immune system to yield unconventional antibody repertoires.

Open Monoclonal Technologies (OMT, now Ligand Pharmaceuticals) produced a set of transgenic rat strains (Omni$\left.\mathrm{Rat}^{\circledR}\right)$ that express a human idiotype repertoire $(22,23)$. Crystal Biosciences (now Ligand Pharmaceuticals) and Sab Biotherapeutics have reported the development of transgenic chickens
(OmniChicken ${ }^{\mathrm{TM}}$ ) and cows (Tc Bovine ${ }^{\mathrm{TM}}$ ), respectively, carrying human repertoires (24-27). The ability to produce human antibody repertoires in evolutionarily divergent systems may be advantageous for helping overcome tolerance. The immune systems of these animals are distinct from conventional antibody generation hosts. As such, they are potentially rich sources of antibody repertoires that may help address challenging targets or design goals.

Non-canonical antibodies have the potential to address practical drug development challenges and to bind to targets in novel ways. The desire to create multispecific therapeutics, with human idiotypes at their core, has seen the development of platforms designed to yield candidates suitable for straightforward conversion into multivalent formats (e.g., common light chain animals) (28). However, the most interesting molecules of this class are derived from heavy-chain-only antibodies (HCAbs) $(29,30)$. Because of their small size and unique mechanism by which they interact with antigens, the $\mathrm{VH}$ domains derived from these antibodies have the potential to bind to classes of targets that regular antibodies cannot. Several groups have developed transgenic HCAb generation platforms that utilize a human antibody repertoire (Harbour Biomed, OMT Therapeutics, Crescendo) (31, 32).

Additional transgenic modifications, distinct from the immunoglobulin loci, can impact the resulting antibody repertoire. Researchers at ImmunoGenes have produced a mouse that over expresses the bovine neonatal Fc receptor (FcRn) (33-35). These animals have an enhanced humoral response and an expanded IgM repertoire (36). Editing the genome by manipulating genes that are known to impact the humoral response would be expected to allow researchers to modify the resulting repertoire. Combining these modifications with a human antibody discovery platform may yield animals capable of producing nonstandard repertoires.

\section{STRATEGIES FOR MAXIMIZING ANTIBODY REPERTOIRE DIVERSITY}

The primary goal for our XenoMouse ${ }^{\circledR}$ immunization campaigns is to maximize antibody repertoire diversity. This serves two purposes: (1) it increases the likelihood of finding antibodies that meet the functional design goals and (2) it increases the probability of identifying lead candidates that are sequence diverse (6). While identification of an antibody satisfying the design goals is a minimal requirement for a successful campaign, the stringent manufacturing criteria of therapeutic antibody development also necessitate the selection of multiple lead candidates with different sequences. If the initial candidate fails biophysical characterization, a unique backup molecule has already been identified.

Since the number of B cells in a mouse at any given moment is $\sim 10^{8}$, and the theoretical diversity of the human antibody repertoire exceeds $10^{11}$, it is reasonable to conclude that an individual mouse can only harbor a fraction of the potential human repertoire $(37,38)$. As such, a fundamental tenet of our strategy is that individual mice can produce unique antibody repertoires. We regularly immunize large cohorts of mice to maximize 
exploration and sampling of the theoretical antibody sequence space. In addition, we have developed multiple strains of XenoMouse $^{\circledR}$ for the purpose of generating the broadest repertoire possible (39). Indeed, we routinely observe biases among the strains with regard to their response to specific antigens. To ensure we raise a diverse response, we include many animals from a variety of strains and genetic backgrounds in our antibody discovery campaigns.

A second guiding principal that governs our approach for maximizing the diversity of antibody repertoires is to develop a comprehensive immunization strategy. Multiple factors should be considered when designing a strategy focused on generating a broad antibody response. These include (1) preparation and presentation of the immunogen, (2) choice of adjuvant, (3) immunization method, and (4) the impact of T-cell tolerance. Although the precise details depend on the nature of the target antigen, our general approach is to use validated forms of immunogens and present them to the immune system in variety of ways.

Preparing the target antigen such that it is an effective immunogen is a critical first step. When considering ways to prepare immunogens, we focus on strategies that are the least likely to disrupt the native structure of the antigen and destroy important epitopes. Our goal is to produce at least three orthogonal types of immunogens for each target: soluble protein, cells expressing the target on the membrane, and DNA expression constructs. These immunogens form the core of our primary immunization strategy and allow us to present multiple forms of the antigen to the immune system.

Many target antigens can be engineered to yield soluble proteins for use as immunogens. The extracellular domains (ECDs) of type-I and -II membrane proteins often exist as modular domains that can be isolated from their native context without compromising their structure. For membrane targets that contain ECDs that are difficult to purify or that cannot easily be overexpressed, an alternative strategy is to artificially tether them to the surface of a cellular expression host (40). This can be done by fusing the ECD to another well-characterized transmembrane domain or by adding a signal sequence for a C-terminal Glycosylphosphatidylinositol (GPI)-anchor (41, 42). Multipass membrane proteins that contain extracellular loops (ECLs) present significant challenges for antigen engineering. Attempts to utilize the isolated loop sequences as peptide immunogens are rarely successful, presumably because they lack native conformation (43). Because of this, we favor genetic and cell-based immunogens for this target class, both of which can be readily produced using the same expression plasmid $(44,45)$. Regardless of how the antigen is engineered, it is important to validate it prior to use. Evidence of the native conformation can be obtained using functional bioassays or by assessing relevant biophysical interactions.

Adjuvants play a pivotal role in potentiating immune responses against antigens. The most widely used adjuvants include the water-in-oil emulsions and the aluminum salts (46). Modern adjuvant research has focused on exploiting the connection between the innate and adaptive immune systems. In particular, toll-like receptor (TLR) agonists have received significant attention because of the important role of TLRs in the activation of innate signaling pathways $(47,48)$. In our experience, adjuvants are absolutely required for generating a robust immune response and diverse antibody repertoires in XenoMouse ${ }^{\circledR}$. Consistent with our results, several studies have demonstrated a broadening of the antibody repertoire as a result of preparing immunogens with specific adjuvants $(49,50)$. Our adjuvant strategy is to leverage the most potent immunomodulatory agents available, while minimizing undesirable effects on the antigen and animal welfare. Although progress continues to be made to develop new adjuvants, we will not cover this here and direct the reader to several excellent reviews (51-54).

A successful immunization campaign requires a suitable immunogen delivery method. Both the form of the antigen and the route by which it is delivered are known to impact the resulting immune response (55-62). While we leverage many traditional methods for delivering protein and cell-based immunogens, we have had tremendous success immunizing XenoMouse ${ }^{\circledR}$ using a genetic approach. Genetic immunization offers many advantages compared with traditional methods. Minimally, it requires only plasmid DNA encoding the antigen of interest which, upon delivery, is taken up by cells and expressed in vivo. The simplicity and native-like expression of this method increases the probability that the natural conformation of the antigen is maintained. This strategy is particularly attractive for complex membrane proteins (e.g., GPCRs, transporters, and ion channels) due to difficulties associated with their expression and purification. We have explored different approaches to improve the effectiveness of DNA immunization. These include frequent and extended boosting regimens, the use of more effective delivery methods, and inclusion of molecular adjuvants. For example, intradermal DNA delivery via a gene gun is a widely used approach that relies on the transfer of plasmid DNA-coated gold particles into the skin via particle bombardment $(63,64)$. The immune response can be potentiated by the inclusion of molecular adjuvants (e.g., cytokines, transcription factors, TLR agonists, etc.) (65-68). Using this method, we routinely generate immune animals within 4-5 weeks that harbor diverse antibody repertoires directed against therapeutically interesting complex membrane targets.

The ability to overcome immune tolerance remains a central problem for antibody discovery using transgenic platforms. For our therapeutic antibody campaigns using XenoMouse ${ }^{\circledR}$, we have exploited observations that tolerance can often be overcome by adding T-cell epitopes (TCEs) to antigens. Consistent with our results, several groups have raised functionally active antibodies against murine antigens in wild-type mouse hosts using this strategy $(69,70)$. The context in which the TCE resides within the antigen plays an important role in determining whether it is efficacious. Intracellular antigen processing, which ultimately yields the peptides for MHC class-II loading and presentation to $\mathrm{T}$ cells, may destroy the TCE if it is presented in a context optimal for proteolytic processing $(71,72)$. Thus, finding the ideal location within the antigen of interest is a critical factor that must be determined empirically.

A number of inbred mouse strains have been identified that have tolerance defects that result in auto-antibody production (73). Breeding a human antibody transgenic mouse to such a strain theoretically produces an animal more prone to break 
tolerance. A more direct approach is to abolish expression of the murine ortholog pertaining to the human target antigen of interest (74). Indeed, we have developed a collection of XenoMouse ${ }^{\circledR}$ knockout lines that carry inactivating mutations in a variety of genes orthologous to human therapeutic targets. However, major caveats are associated with these strategies: (1) many of the autoimmune strains suffer from health issues, (2) some genes are essential for embryonic development and cannot be systemically knocked out, and (3) inactivating genes required for mounting an immune response compromises the ability of the platform to function as desired. Nonetheless, in cases where it is possible, this approach is an effective tolerance-breaking strategy.

\section{STRATEGIES FOR STEERING ANTIBODY REPERTOIRES}

The ability to "steer" the immune response toward a desired outcome has been recognized since Jenner's revolutionary demonstration of induced immunity to the smallpox virus in the $1770 \mathrm{~s}$ (75). Since then, multiple repertoire engineering approaches have been used with varying degrees of success. In the context of therapeutic antibody development, there is often a desire to target (or avoid) a particular epitope on the antigen of interest. Here, we will focus on a selection of current strategies that we use to direct the XenoMouse ${ }^{\circledR}$ immune system to produce a desired antibody repertoire.

One of the most powerful approaches for directing the antibody repertoire toward a specific epitope is to engineer the antigen such that the desired region is effectively presented to the immune system. One way to accomplish this is to selectively express or display the minimal domain carrying the epitope(s) of interest. Importantly, this method also allows us to avoid immunedominant epitopes that otherwise skew the antibody repertoire toward undesired specificities (76-78). We have also had success using human-mouse chimeras and grafting the ECLs of multipass membrane proteins onto related proteins that share a common structure with the target of interest. Grafting the target loops onto a scaffold that retains key intramolecular interactions raises the likelihood that the correct conformational epitopes are retained. Moreover, it is often possible to find a suitable scaffold that has been demonstrated to have more optimal expression characteristics, better cell surface retention properties, or that can tolerate heterologous sequence fusions. This approach is particularly attractive for novel targets where no structural information exists. We have had limited success extracting ECLs and immunizing them as peptides or when grafting them onto heterologous carrier proteins, despite the existence of successful reports $(79,80)$. The success of this strategy depends on the degree to which the design goals are tied to a specific functional epitope or if targeting multiple epitopes within a structural region is permitted.

The safety of therapeutic antibodies must be evaluated in a preclinical setting prior to human trials. This important step of drug development usually necessitates that the clinical candidate cross-reacts to the appropriate preclinical animal species chosen for toxicology $(81,82)$. To ensure our lead candidates can meet this stringent design goal, we frequently incorporate the orthologous antigen from the toxicology species into our immunization protocols. One strategy is to design an immunization campaign that alternates between the human and orthologous antigen to steer the antibody repertoire toward functional antibodies that cross-react to both. Monitoring cross-reactivity throughout the course of the immunization campaign allows further customization through extended or alternative boosting protocols. In our hands, the success of this strategy is tightly correlated with the conservation of functional epitopes and becomes significantly more challenging as evolutionary distances increase.

\section{CONCLUDING REMARKS AND FUTURE PERSPECTIVES}

The convergence of several key technologies, along with our increasing understanding of molecular and cellular immunology, is allowing researchers to purposefully manipulate the immune systems of transgenic animal platforms. Combined with the ability of these systems to produce human antibody repertoires directed against disease-associated target antigens, we are armed with profoundly powerful tools for the discovery of novel therapeutics. Advances in the fields of genetic engineering and immunization have enabled diverse antibody responses to be elicited against a variety of difficult targets. Progress in antigen engineering and immunomodulation have allowed researchers to steer the immune response toward the production of more relevant antibody repertoires.

Despite impressive progress, it is clear that transgenic animal platforms have more to offer. Although we can elicit broad and diverse repertoires, we lack suitable methods to deeply interrogate them. This is particularly problematic when seeking a B cell that produces an antibody with a rare specificity. Most current strategies rely heavily on hybridoma-driven repertoire sampling, a technique known to be notoriously biased and inefficient (83). Multiple variations on direct, single B-cell screening are also used to identify antibodies of interest (84-90). Unfortunately, these methods are generally low throughput, labor intensive, and restricted to simple assays, which limits their usefulness to mine significant fractions of the elicited repertoire. Other methods to display and screen antibody repertoires were developed, in part, to address some of these limitations (e.g., phage display). However, these approaches suffer from the fact that the native pairings are lost, making it even more difficult to recover rare antibodies (91-95).

However, notable advancements in high-throughput repertoire analysis and recovery have recently been made. It is now possible to use next-generation sequencing (NGS) to determine all of the individual sequences that make up the complete antibody repertoire of an animal $(96,97)$. For the first time, researchers can determine the holistic effects of their attempts to influence the repertoire (98). This will clearly impact future attempts to maximize diversity and shape repertoires by giving us unprecedented insight into the consequences of experimentation. Similarly, improvements in high-throughput techniques for single-cell isolation and screening are allowing scientists to apply these techniques to antibody discovery (99-104). Coupled with the ability to determine the corresponding antibody sequences using NGS, deep interrogation of antibody repertoires is within 
reach. These advancements will no doubt allow the recovery of rare antibodies with properties satisfying the demanding design goals of the next generation of therapeutic targets.

\section{AUTHOR CONTRIBUTIONS}

WC and CM both contributed to writing the manuscript.

\section{REFERENCES}

1. Green LL. Transgenic mouse strains as platforms for the successful discovery and development of human therapeutic monoclonal antibodies. Curr Drug Discov Technol (2014) 11(1):74-84. doi:10.2174/15701638113109990038

2. Abdiche YN, Harriman R, Deng X, Yeung YA, Miles A, Morishige W, et al. Assessing kinetic and epitopic diversity across orthogonal monoclonal antibody generation platforms. MAbs (2016) 8(2):264-77. doi:10.1080/194 20862.2015.1118596

3. Chan TD, Brink R. Affinity-based selection and the germinal center response. Immunol Rev (2012) 247(1):11-23. doi:10.1111/j.1600-065X.2012.01118.x

4. Goodnow CC, Vinuesa CG, Randall KL, Mackay F, Brink R. Control systems and decision making for antibody production. Nat Immunol (2010) 11(8):681-8. doi:10.1038/ni.1900

5. Spencer S, Bethea D, Raju TS, Giles-Komar J, Feng Y. Solubility evaluation of murine hybridoma antibodies. MAbs (2012) 4(3):319-25. doi:10.4161/ mabs. 19869

6. Foltz IN, Gunasekaran K, King CT. Discovery and bio-optimization of human antibody therapeutics using the $\mathrm{XenoMouse}(\mathrm{R})$ transgenic mouse platform. Immunol Rev (2016) 270(1):51-64. doi:10.1111/imr.12409

7. Jo M, Jung ST. Engineering therapeutic antibodies targeting G-proteincoupled receptors. Exp Mol Med (2016) 48:e207. doi:10.1038/emm.2015.105

8. Douthwaite JA, Finch DK, Mustelin T, Wilkinson TC. Development of therapeutic antibodies to $\mathrm{G}$ protein-coupled receptors and ion channels: opportunities, challenges and their therapeutic potential in respiratory diseases. Pharmacol Ther (2017) 169:113-23. doi:10.1016/j.pharmthera. 2016.04.013

9. Wilkinson TC. Discovery of functional monoclonal antibodies targeting G-protein-coupled receptors and ion channels. Biochem Soc Trans (2016) 44(3):831-7. doi:10.1042/BST20160028

10. Liu D, Tseng M, Epstein LF, Green L, Chan B, Soriano B, et al. Evaluation of recombinant monoclonal antibody SVmab1 binding to Na V1.7 target sequences and block of human Na V1.7 currents. F1000Res (2016) 5:2764. doi:10.12688/f1000research.9918.1

11. Santos R, Ursu O, Gaulton A, Bento AP, Donadi RS, Bologa CG, et al. A comprehensive map of molecular drug targets. Nat Rev Drug Discov (2017) 16(1):19-34. doi:10.1038/nrd.2016.230

12. Bruggemann M, Osborn MJ, Ma B, Hayre J, Avis S, Lundstrom B, et al. Human antibody production in transgenic animals. Arch Immunol Ther Exp (Warsz) (2015) 63(2):101-8. doi:10.1007/s00005-014-0322-x

13. Jakobovits A. The long-awaited magic bullets: therapeutic human monoclonal antibodies from transgenic mice. Expert Opin Investig Drugs (1998) 7(4):607-14. doi:10.1517/13543784.7.4.607

14. Lonberg N. Human monoclonal antibodies from transgenic mice. Handb Exp Pharmacol (2008) 181:69-97. doi:10.1007/978-3-540-73259-4_4

15. Jakobovits A, Green LL, Hardy MC, Maynard-Currie CE, Tsuda H, Louie DM, et al. Production of antigen-specific human antibodies from mice engineered with human heavy and light chain YACs. Ann N Y Acad Sci (1995) 764:525-35. doi:10.1111/j.1749-6632.1995.tb55878.x

16. Lonberg N, Taylor LD, Harding FA, Trounstine M, Higgins KM, Schramm SR, et al. Antigen-specific human antibodies from mice comprising four distinct genetic modifications. Nature (1994) 368(6474):856-9. doi:10.1038/ $368856 \mathrm{a} 0$

17. Lee EC, Liang Q, Ali H, Bayliss L, Beasley A, Bloomfield-Gerdes T, et al. Complete humanization of the mouse immunoglobulin loci enables efficient therapeutic antibody discovery. Nat Biotechnol (2014) 32(4):356-63. doi: $10.1038 /$ nbt.2825

18. Macdonald LE, Karow M, Stevens S, Auerbach W, Poueymirou WT, Yasenchak J, et al. Precise and in situ genetic humanization of $6 \mathrm{Mb}$ of mouse

\section{ACKNOWLEDGMENTS}

The authors would like to thank Chadwick King, Karyn McFadden, and the anonymous internal Amgen, Inc. reviewers for critical reading of the manuscript. The authors would also like to thank the peer reviewers and editor for helpful comments and suggestions.

immunoglobulin genes. Proc Natl Acad Sci U S A (2014) 111(14):5147-52. doi:10.1073/pnas.1323896111

19. Murphy AJ, Macdonald LE, Stevens S, Karow M, Dore AT, Pobursky K, et al. Mice with megabase humanization of their immunoglobulin genes generate antibodies as efficiently as normal mice. Proc Natl Acad Sci U S A (2014) 111(14):5153-8. doi:10.1073/pnas.1324022111

20. Mompo SM, Gonzalez-Fernandez A. Antigen-specific human monoclonal antibodies from transgenic mice. Methods Mol Biol (2014) 1060:245-76. doi:10.1007/978-1-62703-586-6_13

21. Bruggemann M, Osborn MJ, Ma B, Buelow R. Strategies to obtain diverse and specific human monoclonal antibodies from transgenic animals. Transplantation (2017) 101(8):1770-6. doi:10.1097/TP.0000000000001702

22. Osborn MJ, Ma B, Avis S, Binnie A, Dilley J, Yang X, et al. High-affinity IgG antibodies develop naturally in Ig-knockout rats carrying germline human IgH/Igkappa/Iglambda loci bearing the rat $\mathrm{CH}$ region. J Immunol (2013) 190(4):1481-90. doi:10.4049/jimmunol.1203041

23. Ma B, Osborn MJ, Avis S, Ouisse LH, Menoret S, Anegon I, et al. Human antibody expression in transgenic rats: comparison of chimeric IgH loci with human $\mathrm{VH}, \mathrm{D}$ and $\mathrm{JH}$ but bearing different rat C-gene regions. J Immunol Methods (2013) 40(0-401):78-86. doi:10.1016/j.jim.2013.10.007

24. Kuroiwa Y, Kasinathan P, Sathiyaseelan T, Jiao JA, Matsushita H, Sathiyaseelan J, et al. Antigen-specific human polyclonal antibodies from hyperimmunized cattle. Nat Biotechnol (2009) 27(2):173-81. doi:10.1038/nbt.1521

25. Kuroiwa Y, Kasinathan P, Choi YJ, Naeem R, Tomizuka K, Sullivan EJ, et al. Cloned transchromosomic calves producing human immunoglobulin. Nat Biotechnol (2002) 20(9):889-94. doi:10.1038/nbt727

26. Matsushita H, Sano A, Wu H, Jiao JA, Kasinathan P, Sullivan EJ, et al. Triple immunoglobulin gene knockout transchromosomic cattle: bovine lambda cluster deletion and its effect on fully human polyclonal antibody production. PLoS One (2014) 9(3):e90383. doi:10.1371/journal.pone.0090383

27. Ching KH, Collarini EJ, Abdiche YN, Bedinger D, Pedersen D, Izquierdo S, et al. Chickens with humanized immunoglobulin genes generate antibodies with high affinity and broad epitope coverage to conserved targets. MAbs (2017)10(1):71-80. doi:10.1080/19420862.2017.1386825

28. Moran N. Mouse platforms jostle for slice of humanized antibody market. Nat Biotechnol (2013) 31(4):267-8. doi:10.1038/nbt0413-267

29. Konning D, Zielonka S, Grzeschik J, Empting M, Valldorf B, Krah S, et al. Camelid and shark single domain antibodies: structural features and therapeutic potential. Curr Opin Struct Biol (2017) 45:10-6. doi:10.1016/j. sbi.2016.10.019

30. Muyldermans S. Nanobodies: natural single-domain antibodies. Annu Rev Biochem (2013) 82:775-97. doi:10.1146/annurev-biochem-063011-092449

31. Lou K-J. Crescendo's TKO. SciBX (2010) 3(41). doi:10.1038/scibx.2010.1227

32. Janssens R, Dekker S, Hendriks RW, Panayotou G, van Remoortere A, San JK, et al. Generation of heavy-chain-only antibodies in mice. Proc Natl Acad Sci US A (2006) 103(41):15130-5. doi:10.1073/pnas.0601108103

33. Vegh A, Cervenak J, Jankovics I, Kacskovics I. FcRn overexpression in mice results in potent humoral response against weakly immunogenic antigen. MAbs (2011) 3(2):173-80. doi:10.4161/mabs.3.2.14462

34. Schneider Z, Cervenak J, Baranyi M, Papp K, Prechl J, Laszlo G, et al. Transgenic expression of bovine neonatal $F_{c}$ receptor in mice boosts immune response and improves hybridoma production efficiency without any sign of autoimmunity. Immunol Lett (2011) 137(1-2):62-9. doi:10.1016/j. imlet.2011.02.018

35. Cervenak J, Bender B, Schneider Z, Magna M, Carstea BV, Liliom K, et al. Neonatal FcR overexpression boosts humoral immune response in transgenic mice. J Immunol (2011) 186(2):959-68. doi:10.4049/jimmunol.1000353

36. Cervenak J, Kurrle R, Kacskovics I. Accelerating antibody discovery using transgenic animals overexpressing the neonatal Fc receptor as a result 
of augmented humoral immunity. Immunol Rev (2015) 268(1):269-87. doi:10.1111/imr.12364

37. Gaudin E, Rosado M, Agenes F, McLean A, Freitas AA. B-cell homeostasis, competition, resources, and positive selection by self-antigens. Immunol Rev (2004) 197:102-15. doi:10.1111/j.0105-2896.2004.0095.x

38. Glanville J, Zhai W, Berka J, Telman D, Huerta G, Mehta GR, et al. Precise determination of the diversity of a combinatorial antibody library gives insight into the human immunoglobulin repertoire. Proc Natl Acad Sci U S A (2009) 106(48):20216-21. doi:10.1073/pnas.0909775106

39. Jakobovits A, Amado RG, Yang X, Roskos L, Schwab G. From XenoMouse technology to panitumumab, the first fully human antibody product from transgenic mice. Nat Biotechnol (2007) 25(10):1134-43. doi:10.1038/nbt1337

40. Dreyer AM, Beauchamp J, Matile H, Pluschke G. An efficient system to generate monoclonal antibodies against membrane-associated proteins by immunisation with antigen-expressing mammalian cells. BMC Biotechnol (2010) 10:87. doi:10.1186/1472-6750-10-87

41. Spiller OB, Harris CL, Morgan BP. Efficient generation of monoclonal antibodies against surface-expressed proteins by hyperexpression in rodent cells. JImmunol Methods (1999) 224(1-2):51-60. doi:10.1016/ S0022-1759(99)00008-3

42. Rose N, Pinho-Nascimento CA, Ruggieri A, Favuzza P, Tamborrini M, Roth $\mathrm{H}$, et al. Generation of monoclonal antibodies against native viral proteins using antigen-expressing mammalian cells for mouse immunization. BMC Biotechnol (2016) 16(1):83. doi:10.1186/s12896-016-0314-5

43. Irving MB, Craig L, Menendez A, Gangadhar BP, Montero M, van Houten NE, et al. Exploring peptide mimics for the production of antibodies against discontinuous protein epitopes. Mol Immunol (2010) 47(5):1137-48. doi:10.1016/j. molimm.2009.10.015

44. Lin FF, Elliott R, Colombero A, Gaida K, Kelley L, Moksa A, et al. Generation and characterization of fully human monoclonal antibodies against human Orail for autoimmune disease. J Pharmacol Exp Ther (2013) 345(2):225-38. doi:10.1124/jpet.112.202788

45. Yan H, Gu W, Yang J, Bi V, Shen Y, Lee E, et al. Fully human monoclonal antibodies antagonizing the glucagon receptor improve glucose homeostasis in mice and monkeys. J Pharmacol Exp Ther (2009) 329(1):102-11. doi:10.1124/jpet.108.147009

46. McKee AS, Marrack P. Old and new adjuvants. Curr Opin Immunol (2017) 47:44-51. doi:10.1016/j.coi.2017.06.005

47. Dowling JK, Mansell A. Toll-like receptors: the swiss army knife of immunity and vaccine development. Clin Transl Immunology (2016) 5(5):e85. doi:10.1038/cti.2016.22

48. Vidya MK, Kumar VG, Sejian V, Bagath M, Krishnan G, Bhatta R. Toll-like receptors: significance, ligands, signaling pathways, and functions in mammals. Int Rev Immunol (2018) 37(1):20-36. doi:10.1080/08830185.2017.13 80200

49. Khurana S, Verma N, Yewdell JW, Hilbert AK, Castellino F, Lattanzi M, et al. MF59 adjuvant enhances diversity and affinity of antibody-mediated immune response to pandemic influenza vaccines. Sci Transl Med (2011) 3(85):85ra48. doi:10.1126/scitranslmed.3002336

50. Khurana S, Chearwae W, Castellino F, Manischewitz J, King LR, Honorkiewicz A, et al. Vaccines with MF59 adjuvant expand the antibody repertoire to target protective sites of pandemic avian H5N1 influenza virus. Sci Transl Med (2010) 2(15):15ra5. doi:10.1126/scitranslmed.3000624

51. Apostolico Jde S, Lunardelli VA, Coirada FC, Boscardin SB, Rosa DS. Adjuvants: classification, modus operandi, and licensing. JImmunol Res (2016) 2016:1459394. doi:10.1155/2016/1459394

52. Garcon N, Di Pasquale A. From discovery to licensure, the adjuvant system story. Hum Vaccin Immunother (2017) 13(1):19-33. doi:10.1080/21645515. 2016.1225635

53. Moyer TJ, Zmolek AC, Irvine DJ. Beyond antigens and adjuvants: formulating future vaccines. J Clin Invest (2016) 126(3):799-808. doi:10.1172/JCI81083

54. Petrovsky N. Comparative safety of vaccine adjuvants: a summary of current evidence and future needs. Drug Safety (2015) 38(11):1059-74. doi:10.1007/ s40264-015-0350-4

55. Gramzinski RA, Millan CL, Obaldia N, Hoffman SL, Davis HL. Immune response to a hepatitis B DNA vaccine in Aotus monkeys: a comparison of vaccine formulation, route, and method of administration. Mol Med (1998) 4(2):109-18.
56. Ito K, Ito K, Shinohara N, Kato S. DNA immunization via intramuscular and intradermal routes using a gene gun provides different magnitudes and durations on immune response. Mol Immunol (2003) 39(14):847-54. doi:10.1016/S0161-5890(03)00024-5

57. Song JM, Kim YC, Lipatov AS, Pearton M, Davis CT, Yoo DG, et al. Microneedle delivery of $\mathrm{H} 5 \mathrm{~N} 1$ influenza virus-like particles to the skin induces long-lasting B- and T-cell responses in mice. Clin Vaccine Immunol (2010) 17(9):1381-9. doi:10.1128/CVI.00100-10

58. Temchura V, Kalinin S, Nabi G, Tippler B, Niezold T, Uberla K. Divergence of primary cognate B- and T-cell proliferative responses to subcutaneous and intravenous immunization with virus-like particles. Viruses (2014) 6(8):3334-47. doi:10.3390/v6083334

59. Wang S, Zhang C, Zhang L, Li J, Huang Z, Lu S. The relative immunogenicity of DNA vaccines delivered by the intramuscular needle injection, electroporation and gene gun methods. Vaccine (2008) 26(17):2100-10. doi:10.1016/j. vaccine.2008.02.033

60. Cai MS, Deng SX, Li ML. Comparison of the immune responses in BALB/C mice following immunization with DNA-based and live attenuated vaccines delivered via different routes. Vaccine (2013) 31(9):1353-6. doi:10.1016/j. vaccine.2012.09.009

61. McKay PF, King DF, Mann JF, Barinaga G, Carter D, Shattock RJ. TLR4 and TLR7/8 adjuvant combinations generate different vaccine antigen-specific immune outcomes in minipigs when administered via the ID or IN routes. PLoS One (2016) 11(2):e0148984. doi:10.1371/journal.pone.0148984

62. Shakya AK, Gill HS. A comparative study of microneedle-based cutaneous immunization with other conventional routes to assess feasibility of microneedles for allergy immunotherapy. Vaccine (2015) 33(33):4060-4. doi:10.1016/j.vaccine.2015.06.042

63. Barry MA, Barry ME, Johnston SA. Production of monoclonal antibodies by genetic immunization. Biotechniques (1994) 16(4):616-8.

64. Tang DC, DeVit M, Johnston SA. Genetic immunization is a simple method for eliciting an immune response. Nature (1992) 356(6365):152-4. doi:10.1038/356152a0

65. Ramanathan MP, Kutzler MA, Kuo YC, Yan J, Liu H, Shah V, et al. Coimmunization with an optimized IL15 plasmid adjuvant enhances humoral immunity via stimulating B cells induced by genetically engineered DNA vaccines expressing consensus JEV and WNV E DIII. Vaccine (2009) 27(32):4370-80. doi:10.1016/j.vaccine.2009.01.137

66. Flingai S, Czerwonko M, Goodman J, Kudchodkar SB, Muthumani K, Weiner DB. Synthetic DNA vaccines: improved vaccine potency by electroporation and co-delivered genetic adjuvants. Front Immunol (2013) 4:354. doi:10.3389/fimmu.2013.00354

67. Li L, Petrovsky N. Molecular adjuvants for DNA vaccines. Curr Issues Mol Biol (2017) 22:17-40. doi:10.21775/cimb.022.017

68. Suschak JJ, Williams JA, Schmaljohn CS. Advancements in DNA vaccine vectors, non-mechanical delivery methods, and molecular adjuvants to increase immunogenicity. Hum Vaccin Immunother (2017) 13(12):2837-48. doi:10.1080/21645515.2017.1330236

69. Zhou H, Wang Y, Wang W, Jia J, Li Y, Wang Q, et al. Generation of monoclonal antibodies against highly conserved antigens. PLoS One (2009) 4(6):e6087. doi:10.1371/journal.pone.0006087

70. Percival-Alwyn JL, England E, Kemp B, Rapley L, Davis NH, McCarthy GR, et al. Generation of potent mouse monoclonal antibodies to self-proteins using T-cell epitope "tags". MAbs (2015) 7(1):129-37. doi:10.4161/1942086 2.2014.985489

71. Antoniou AN, Blackwood SL, Mazzeo D, Watts C. Control of antigen presentation by a single protease cleavage site. Immunity (2000) 12(4):391-8. doi:10.1016/S1074-7613(00)80191-0

72. Sercarz EE, Maverakis E. Mhc-guided processing: binding of large antigen fragments. Nat Rev Immunol (2003) 3(8):621-9. doi:10.1038/nri1149

73. Perry D, Sang A, Yin Y, Zheng YY, Morel L. Murine models of systemic lupus erythematosus. JBiomed Biotechnol (2011) 2011:271694. doi:10.1155/2011/271694

74. Hrabovska A, Bernard V, Krejci E. A novel system for the efficient generation of antibodies following immunization of unique knockout mouse strains. PLoS One (2010) 5(9):e12892. doi:10.1371/journal.pone.0012892

75. Jenner E. Inquiry into the Causes and Effects of the Variolae Vaccine. London: Sampson Low (1798). 
76. Angeletti D, Gibbs JS, Angel M, Kosik I, Hickman HD, Frank GM, et al. Defining B cell immunodominance to viruses. Nat Immunol (2017) 18(4):456-63. doi:10.1038/ni.3680

77. Havenar-Daughton C, Lee JH, Crotty S. Tfh cells and HIV bnAbs, an immunodominance model of the HIV neutralizing antibody generation problem. Immunol Rev (2017) 275(1):49-61. doi:10.1111/imr.12512

78. Silva M, Nguyen TH, Philbrook P, Chu M, Sears O, Hatfield S, et al. Targeted elimination of immunodominant B cells drives the germinal center reaction toward subdominant epitopes. Cell Rep (2017) 21(13):3672-80. doi:10.1016/j.celrep.2017.12.014

79. Bolchi A, Canali E, Santoni A, Spagnoli G, Viarisio D, Accardi R, et al. Thioredoxin-displayed multipeptide immunogens. Methods Mol Biol (2015) 1348:137-51. doi:10.1007/978-1-4939-2999-3_14

80. Chakraborty K, Durani V, Miranda ER, Citron M, Liang X, Schleif W, et al. Design of immunogens that present the crown of the HIV-1 V3 loop in a conformation competent to generate 447-52D-like antibodies. Biochem J (2006) 399(3):483-91. doi:10.1042/BJ20060588

81. Brennan FR, Cavagnaro J, McKeever K, Ryan PC, Schutten MM, Vahle J, et al. Safety testing of monoclonal antibodies in non-human primates: case studies highlighting their impact on human risk assessment. MAbs (2018) 10(1):1-17. doi:10.1080/19420862.2017.1389364

82. Muller PY, Brennan FR. Safety assessment and dose selection for firstin-human clinical trials with immunomodulatory monoclonal antibodies. Clin Pharmacol Ther (2009) 85(3):247-58. doi:10.1038/clpt.2008.273

83. Dubois AR, Buerckert JP, Sinner R, Faison WJ, Molitor AM, Muller CP. High-resolution analysis of the B cell repertoire before and after polyethylene glycol fusion reveals preferential fusion of rare antigen-specific B cells. Hum Antibodies (2016) 24(1-2):1-15. doi:10.3233/HAB-150288

84. Akbari S, Pirbodaghi T. A droplet-based heterogeneous immunoassay for screening single cells secreting antigen-specific antibodies. Lab Chip (2014) 14(17):3275-80. doi:10.1039/c4lc00082j

85. Carbonetti S, Oliver BG, Vigdorovich V, Dambrauskas N, Sack B, Bergl E, et al. A method for the isolation and characterization of functional murine monoclonal antibodies by single B cell cloning. J Immunol Methods (2017) 448:66-73. doi:10.1016/j.jim.2017.05.010

86. Lin Z, Chiang NY, Chai N, Seshasayee D, Lee WP, Balazs M, et al. In vivo antigen-driven plasmablast enrichment in combination with antigen-specific cell sorting to facilitate the isolation of rare monoclonal antibodies from human B cells. Nat Protoc (2014) 9(7):1563-77. doi:10.1038/nprot. 2014.104

87. Ouisse LH, Gautreau-Rolland L, Devilder MC, Osborn M, Moyon M, Visentin J, et al. Antigen-specific single B cell sorting and expression-cloning from immunoglobulin humanized rats: a rapid and versatile method for the generation of high affinity and discriminative human monoclonal antibodies. BMC Biotechnol (2017) 17(1):3. doi:10.1186/s12896-016-0322-5

88. Starkie DO, Compson JE, Rapecki S, Lightwood DJ. Generation of recombinant monoclonal antibodies from immunised mice and rabbits via flow cytometry and sorting of antigen-specific IgG+ memory B cells. PLoS One (2016) 11(3):e0152282. doi:10.1371/journal.pone.0152282

89. Tiller T. Single B cell antibody technologies. N Biotechnol (2011) 28(5):453-7. doi:10.1016/j.nbt.2011.03.014

90. Zhang Z, Liu H, Guan Q, Wang L, Yuan H. Advances in the isolation of specific monoclonal rabbit antibodies. Front Immunol (2017) 8:494. doi:10.3389/ fimmu.2017.00494

91. Sorouri M, Fitzsimmons SP, Aydanian AG, Bennett S, Shapiro MA. Diversity of the antibody response to tetanus toxoid: comparison of hybridoma library to phage display library. PLoS One (2014) 9(9):e106699. doi:10.1371/journal. pone. 0106699

92. Kramer RA, Marissen WE, Goudsmit J, Visser TJ, Clijsters-Van der Horst M, Bakker AQ, et al. The human antibody repertoire specific for rabies virus glycoprotein as selected from immune libraries. Eur JImmunol (2005) 35(7):2131-45. doi:10.1002/eji.200526134

93. Marks JD, Hoogenboom HR, Bonnert TP, McCafferty J, Griffiths AD, Winter G. By-passing immunization. Human antibodies from V-gene libraries displayed on phage. J Mol Biol (1991) 222(3):581-97. doi:10.1016/00222836(91)90498-U

94. Meijer PJ, Andersen PS, Haahr Hansen M, Steinaa L, Jensen A, Lantto J, et al. Isolation of human antibody repertoires with preservation of the natural heavy and light chain pairing. J Mol Biol (2006) 358(3):764-72. doi:10.1016/j. jmb.2006.02.040

95. Saggy I, Wine Y, Shefet-Carasso L, Nahary L, Georgiou G, Benhar I. Antibody isolation from immunized animals: comparison of phage display and antibody discovery via V gene repertoire mining. Protein Eng Des Sel (2012) 25(10):539-49. doi:10.1093/protein/gzs060

96. Friedensohn S, Khan TA, Reddy ST. Advanced methodologies in highthroughput sequencing of immune repertoires. Trends Biotechnol (2017) 35(3):203-14. doi:10.1016/j.tibtech.2016.09.010

97. Cortina-Ceballos B, Godoy-Lozano EE, Samano-Sanchez H, AguilarSalgado A, Velasco-Herrera Mdel C, Vargas-Chavez C, et al. Reconstructing and mining the B cell repertoire with ImmunediveRsity. MAbs (2015) 7(3):516-24. doi:10.1080/19420862.2015.1026502

98. Olafsdottir T, Lindqvist M, Harandi AM. Molecular signatures of vaccine adjuvants. Vaccine (2015) 33(40):5302-7. doi:10.1016/j.vaccine.2015.04.099

99. DeKosky BJ, Kojima T, Rodin A, Charab W, Ippolito GC, Ellington AD, et al. In-depth determination and analysis of the human paired heavy- and light-chain antibody repertoire. Nat Med (2015) 21(1):86-91. doi:10.1038/ nm.3743

100. Parola C, Neumeier D, Reddy ST. Integrating high-throughput screening and sequencing for monoclonal antibody discovery and engineering. Immunology (2018) 153(1):31-41. doi:10.1111/imm.12838

101. Seah YFS, Hu H, Merten CA. Microfluidic single-cell technology in immunology and antibody screening. Mol Aspects Med (2018) 59:47-61. doi:10.1016/j.mam.2017.09.004

102. Fitzgerald V, Leonard P. Single cell screening approaches for antibody discovery. Methods (2017) 116:34-42. doi:10.1016/j.ymeth.2016.11.006

103. Mettler Izquierdo S, Varela S, Park M, Collarini EJ, Lu D, Pramanick S, et al. High-efficiency antibody discovery achieved with multiplexed microscopy. Microscopy (Oxf) (2016) 65(4):341-52. doi:10.1093/jmicro/dfw014

104. Tickle S, Howells L, O’Dowd V, Starkie D, Whale K, Saunders M, et al. A fully automated primary screening system for the discovery of therapeutic antibodies directly from B cells. J Biomol Screen (2015) 20(4):492-7. doi:10.1177/1087057114564760

Conflict of Interest Statement: WC and CM are full-time employees of, and hold stock in, Amgen, Inc.

Copyright $\odot 2018$ Chen and Murawsky. This is an open-access article distributed under the terms of the Creative Commons Attribution License (CC BY). The use, distribution or reproduction in other forums is permitted, provided the original author(s) and the copyright owner are credited and that the original publication in this journal is cited, in accordance with accepted academic practice. No use, distribution or reproduction is permitted which does not comply with these terms. 